\title{
Intertemporal Evaluation Criteria for Climate Change Policy: Basic Ethical Issues
}

\author{
Wolfgang Buchholz ${ }^{1}$ and Michael Schymura ${ }^{2}$ \\ ${ }^{1}$ University of Regensburg and CESifo, Munich \\ ${ }^{2}$ Centre for European Economic Research (ZEW), Mannheim
}

Germany

\section{Introduction}

The results of cost benefit analysis crucially depend on the welfare criteria that are used to evaluate the streams of well-being over time generated by the investment projects under consideration. In economics and philosophy there is a long lasting and rather controversial debate as to which type of intertemporal social welfare function and, in particular, which social discount rate should be applied. This debate has been revitalized in the last few years because, especially since the release of the Stern Review in 2006, it has become clear which dramatic effect the choice of the social discount rate has on the design of climate policy. In this context it is important to decide how costs and benefits should be shared between generations and, in particular, to which extent the interests of future generations should be taken into account when projects with long-run consequences are carried out. From this perspective the choice of a specific intertemporal evaluation criterion becomes a matter of ethics, i.e. of justice between generations.

There exist two opposing "schools" in economics which have completely different positions concerning the importance of intergenerational ethics for intertemporal evaluation (see Aldy et al. (2010), p.912). On the one hand there is the positive ("descriptive") school for which ethical judgment is redundant since behavior of existing individuals and thus empirically observable market interest rates should be the benchmark for the determination of the social discount rate. On the other hand there is the normative ("prescriptive") school which has its roots in classical welfare economics and for which explicitly formulated normative criteria are of much importance. For this school an ethically oriented debate on the properties and implications of different intertemporal evaluation criteria and their normative foundations is essential (see Atkinson, A. (2011) for a general discussion on the relationship between ethics and welfare economics.). In the climate change literature arguments of both schools often are confounded which causes much misunderstanding and makes the debate on the appropriate method for intertemporal evaluation rather opaque (see e.g. Kaplow, L., Moyer, E. and D. A. Weisbach (2010) as some critical reflections on the debate).

In this paper we will adopt the perspective of the normative school (see also Roemer J. (2011), for an excellent defense of the ethical position). Our main objective then is to present the most important ethical issues that, particularly in the context of climate policy, are relevant for the choice of intertemporal welfare criteria. We will proceed as follows. In Section 2 we present various classes of intertemporal social welfare functions well-known from optimal 
growth theory (i.e. maximin, undiscounted utilitarianism, discounted utilitarianism and some recently developed hybrid criteria) and discuss which desirable and undesirable properties they have. In Section 3 we explore whether ethical criteria can also be employed to determine the parameter values (or at least to delimit their range) which, after the choice of some type of intertemporal social welfare function, are needed to specify the concrete criterion by which decisions on climate policy are made. In Section 4 we conclude and discuss some implications our general considerations may have for climate change policy.

\section{Ethically relevant properties of different types of intertemporal social welfare functions}

\subsection{Preliminaries}

In common with the literature we assume that $c_{t}$ denotes well-being in period of time $t=$ $1,2, \ldots$ Thus the vector of various determinants of well-being, i.e. material consumption, leisure, environmental quality etc, is mapped into the real-valued indicator $c_{t}$. The severe problems of measurement and aggregation of $c_{t}$ are not treated in this paper ${ }^{1}$. Purely for terminological convenience, we identify the variable $c_{t}$ with consumption in period $t$ in all that follows. Time is discrete, with each period of time $t=1,2, \ldots$ representing just the lifespan of one single generation. So generations do not overlap, and for the sake of simplification, we suppose that population is constant over time thus neglecting the ethical aspects of population change $^{2}$. If some technology and some initial resource endowment are given there is a class $\Gamma$ of feasible consumption paths $\left(c_{1}, c_{2}, \ldots\right)$ of infinite length. These consumption paths are evaluated by an intertemporal social welfare function $W($.$) which is weakly monotone in all$ variables and may assume values in the interval $[-\infty,+\infty]$. We now consider different types of those social welfare functions as suggested by the literature.

\subsection{Maximin}

Maximin as a criterion for intertemporal evaluation dates back to Rawls' "difference principle" (although Rawls, J. (1971) himself did neither accept the denomination "maximin" nor the application of this criterion in the intergenerational context). As an attempt to be "plus Rawlsien que le Rawls" - it was Solow, R. (1974) who applied this criterion to the Dasgupta-Heal-Solow growth model, in which the input of an exhaustible resource is continually substituted by reproducible man-made capital. Given an infinite number of generations the minimum level of consumption along a given consumption path may not exist, such that the maximin social welfare function must in this case be defined as

$$
W\left(c_{1}, c_{2}, \ldots\right)=\inf _{t=1,2, \ldots} c_{t}
$$

This social welfare function satisfies two commonly shared ethical objectives that play a major role in the intergenerational context.

(i) All generations have an equal weight in social evaluation. In particular future generations are not discriminated against simply because they have the bad luck to appear later on the time axis. This intergenerational neutrality also means that the value of the social welfare

\footnotetext{
${ }^{1}$ d'Aspremont, C. and Gevers, L. (1977) offer a very comprehensive axiomatic approach towards different social welfare functions. Roemer, J. (1996) summarizes the extensive literature and contributions that deal with the measurability of well-being and its relevance for social welfare comparisons.

${ }^{2}$ We refer the reader who is interested in situations with a changing population to Blackorby, C. , Bossert, W. and Donaldson, D. (1995).
} 
function (1) is not changed even if an infinite permutation of a given consumption path is made. For a long time (see already Sidgwick, H. (1874)), equal treatment of generations has been considered to be the basic requirement for intergenerational fairness. Maximin also respects some albeit rather weak version of the Pareto principle: If consumption does not decrease for any generation the new path obviously is not worse than the original one.

(ii) The maximin rule (1) implements specific non-decreasing and thus sustainable paths as optimal solutions: Assume that there exists a strictly positive consumption level $\bar{c}$ that, for the given technology and the given initial resource endowment, can be attained by any generation. Then it is clearly excluded by application of (1) that some later generation's consumption falls below $\bar{c}$ while some earlier generation enjoys a consumption level above $\bar{c}$. If such a constant consumption path $(\bar{c}, \bar{c}, \ldots)$ is Pareto optimal it maximizes social welfare according to (1) among all feasible paths as in Solow, R. (1974) classical paper.

Even though the maximin rule shows these ethically appealing properties it also has some serious disadvantages, which limit its usefulness as a criterion for dealing with intertemporal resource allocation issues. This standard view may, however, be challenged if the economy's state of development is already very high and maximin does not apply to levels of material consumption but to basic and partly non-substitutable goods as staple food or health (see Roemer J. (2011)).

(i) Maximin does not respect more demanding versions of the Pareto criterion because it is insensitive to increases in consumption if the minimum/infimum of consumption does not change. In particular, the strong Pareto principle is violated, which means that any increase of consumption along a given path should lead to a strictly preferred new path. To give an example just consider the two consumption paths $\left(\frac{1}{2}, \frac{1}{3}, \frac{1}{4}, \ldots\right)$ and $\left(1, \frac{2}{3}, \frac{1}{2}, \ldots\right)$. Both have the same infimum equal to zero but the second path has a higher level of consumption than the first one not only in one but even in each period of time. In the case of a finite number of generations strong Pareto can be obtained by adopting the leximin criterion, but with an infinite number of generations such an extension is neither straightforward nor does it allow a comparison of all paths (see e.g. Asheim, G. B. (1991)).

(ii) The maximin criterion excludes any investment of an earlier generation to increase well-being of future generations above the level enjoyed by itself - irrespective of the extent of that increase and the number of future generations which would benefit from this sacrifice. To give an example we start from the constant consumption path $(1,1,1, \ldots)$ and assume that the economy is so productive that the path $\left(\frac{999}{1000}, 2,2, \ldots\right)$ is also technically feasible. I.e. if one single generation (the first one) makes a minor sacrifice of only $\frac{1}{1000}$ units of consumption each subsequent generation could double its level of well-being. Nevertheless, the maximin rule deems this path inferior to the original constant consumption path. Strict application of maximin thus condemns the economy to stagnation and precludes economic growth based on savings and investment. It was this reason why Rawls, J. (1971) did not recommend the difference principle for making choices in the intergenerational context.

\subsection{Undiscounted utilitarianism}

In his seminal paper on optimal growth theory Ramsey, F. (1928) used undiscounted utilitarianism to evaluate and compare feasible consumption paths. This approach shares some advantages and disadvantages with the maximin rule but has merits and shortcomings of its own. The standard version of an undiscounted utilitarian social welfare functions reads as

$$
W\left(c_{1}, c_{2}, \ldots\right)=\sum_{t=1}^{\infty} u\left(c_{t}\right)
$$


where $u(c)$ - usually defined for all consumption levels $c>0$ - is a strictly monotone increasing utility function through which the well-being of each generation is assessed before it enters social evaluation but which is not meant to be a felicity function in the sense of classical utilitarianism (see Kaplow, L. (2010) and Kaplow, L., Moyer, E. and D. A. Weisbach (2010) for this conceptual distinction). Often an isoelastic utility function given by $u(c)=\frac{c^{1-\eta}}{1-\eta}$ (or equivalently $u(c)=\frac{c^{1-\eta}-1}{1-\eta}$ ) is employed where the elasticity of marginal utility $\eta \geq 0$ (with $\eta \neq 1$ ) indicates the degree of inequality aversion in social evaluation. For $\eta=1$ the utility function is defined as $\ln c$ (which is justified since $\lim _{\eta \rightarrow 1}=\frac{c^{1-\eta}-1}{1-\eta}=\ln c, \forall c>0$ ). The main ethical advantages of undiscounted utilitarianism are as follows:

(i) In common with the maximin rule application of an undiscounted utilitarian social welfare function implies equal treatment of all generations and thus respects the fundamental postulate for intergenerational justice. Welfare is not changed when the consumption levels of a finite number of generations are permuted if, as assumed in (2), the utility function $u(c)$ is the same for all periods. Concerning distribution in the atemporal setting, i.e. within a society in a certain period of time, it is quite common in welfare economics to make judgments with unweighted sums of utility.

(ii) Undiscounted utilitarianism ensures sustainable development if the economy under consideration is productive in an intuitive sense: If some generation makes a consumption sacrifice to expand the economy's capital stock then it will be possible for some later generation to increase its consumption by more than this earlier sacrifice. Then it follows from a general argument (see Asheim, G. B., Buchholz, W. and Tungodden, B. (2001)) that a somewhere decreasing consumption path will never maximize a welfare function of type (2). So it is ensured that only non-decreasing paths are selected by applying an undiscounted utilitarian criterion. Along such paths no generation consumes more than it concedes to its successors, which gives sustainability.

(iii) If, as is usually assumed, the utility function $u(c)$ is concave, a rank-preserving Pigou-Dalton transfer from a rich generation with high consumption to a poorer generation increases aggregate welfare (2) (see in a general welfare theoretic framework Atkinson, A. (1970)). Thus undiscounted utilitarianism is also useful to take equality of the distribution of well-being among generations into account which, as an ethical objective, is conceptually different from the equal treatment of generations (see Asheim, G. B. (1991)). Employing utility functions $u(c)$ with more or less curvature, i.e. varying the parameter $\eta$ in the case of an isoelastic utility function, makes it possible to capture different degrees of inequality aversion in social evaluation. Then the maximin criterion is the extreme case where inequality aversion $\eta$ is infinite. Classical utilitarianism, where $u(c)=c$ and the pure consumption levels are summed up in (2), reflects the opposite extreme where inequality aversion is completely absent.

On the other hand undiscounted utilitarianism has some properties which are less desirable. (i) For any utility function $u(c)$ the utility sum of many consumption paths will be plus or minus infinity. Simple comparisons of the scalars obtained by (2) will not provide a ranking of these paths. But one may readily refine the ranking somehow by using overtaking or catching up criteria. Thus, e.g., a consumption path $\left(c_{1}^{a}, c_{2}^{a}, \ldots\right)$ is strictly preferred to a consumption path $\left(c_{1}^{b}, c_{2}^{b}, \ldots\right)$ if there is a period $\tilde{T}$ such that for all $T>\tilde{T}$ the inequality

$$
\sum_{t=1}^{T} u\left(c_{t}^{a}\right)>\sum_{t=1}^{T} u\left(c_{t}^{b}\right)
$$


holds (as a pioneering contribution on this overtaking criterion see v. Weizsäcker, C.C. (1965)). Weak preference is obtained if condition (3) is fulfilled with weak inequality $\geq$. For fundamental reasons, however, one cannot further extend the partial ordering given by (3) in a way that respects stronger versions of the Pareto principle and permits comparisons between any two consumption paths.

(ii) While in a productive economy maximin excessively favors the present, undiscounted utilitarianism may excessively favor the future, demanding very high savings from earlier generations. To illustrate this, we assume that, given a strictly increasing utility function and starting from a constant consumption path $(\bar{c}, \bar{c}, \ldots)$, the consumption sacrifice $s$ in the first generation allows all subsequent generations to increase their consumption by some amount $\epsilon>0$. Then, as long as $u(\bar{c}-s)>-\infty$, the consumption path $(\bar{c}-s, \bar{c}+\epsilon, \bar{c}+\epsilon, \ldots)$ will dominate $(\bar{c}, \bar{c}, \ldots)$ irrespective of how small $\epsilon$ is. Under undiscounted utilitarianism the infinite number of future generations thus gains some dictatorial position towards any finite number of earlier generations. This well-known argument against undiscounted utilitarianism (see already Chakravarty, S. (1969) and Rawls, J. (1971) and more recently Arrow (1999) and Asheim, G. B. (2010)), however, needs some qualification as it does not hold for any path from which saving starts. Suppose for instance that the utility function is $u(c)=-c^{-1}$ and that the initial consumption path is $(1,2,4,8, \ldots)$ which then has aggregate welfare -2 . Further assume that generation 1 saves $\frac{1}{4}$ which, for a certain technology, permits an increase of consumption of any subsequent generation by the uniform amount $\frac{1}{10}$. The new consumption stream $\left(\frac{3}{4}, 2+\frac{1}{10}, 4+\frac{1}{10}, 8+\frac{1}{10}, \ldots\right)=\left(\frac{3}{4}, \frac{21}{10}, \frac{41}{10}, \frac{81}{10}, \ldots\right)$ is Pareto inferior to the consumption path $\left(\frac{3}{4}, \frac{21}{20} \cdot 2, \frac{21}{20} \cdot 4, \frac{21}{20} \cdot 8, \ldots\right)$ whose welfare is $-\frac{4}{3}-\frac{20}{21} \cdot 1=-\frac{48}{21}<$ -2 . So the new path is inferior to the original one, which means that the investment of generation 1 does not improve welfare even though all generations from generation 2 on benefit from an equal increase of consumption. If saving of generation 1 exceeded $\frac{1}{2}$ then any increase in future consumption along the given initial path would not be sufficient to restore welfare to its original level. Therefore, if we do not start from a constant, but from a strictly monotone increasing consumption path, undiscounted utilitarianism is able to prevent excessive saving and to restrict the rate of growth to an ethically acceptable degree (see Asheim, G. B. and Buchholz, W. (2003) for a further elaboration of this argument).

\subsection{Discounted utilitarianism}

Most frequently intertemporal evaluation is performed using discounted utilitarian social welfare functions which give utility of future generations less weight than utility of earlier ones. This type of social welfare functions is defined by

$$
W\left(c_{1}, c_{2}, \ldots\right)=\sum_{t=1}^{\infty} \delta_{t} u\left(c_{t}\right)
$$

In (4) the function $u\left(c_{t}\right)$ again represents utility of consumption and $\left(\delta_{t}\right)_{t=1,2, \ldots}$ is a non-increasing sequence of utility discount factors with $\sum_{t=1}^{\infty} \delta_{t}<\infty$. These utility discount factors indicate how much utility in period $t$ counts in terms of period 1 such that naturally $\delta_{1}=1$. Traditionally, $\left(\delta_{t}\right)_{t=1,2, \ldots}$ is assumed to fall geometrically, i.e. $\delta_{t}=\delta^{t-1}$ where $\delta=\frac{1}{1+\rho}$ 
and $\rho \geq 0$ is the constant discount or time preference rate ${ }^{3}$. If $\delta=1$ all generations are treated equally, and undiscounted utilitarianism is obtained as a special case of (4).

Discounted utilitarianism has several desirable properties.

(i) For consumption paths that are strictly bounded away from zero and bounded above social welfare according to (4) is a well-defined scalar such that a complete ordering is obtained in an obvious way. Completeness is an attractive feature if one shares the view that a rational ethical observer should always be able to decide whether one of two arbitrarily given consumption paths is better than the other (or whether they are equivalent). But it may be questioned how important completeness really is, i.e. whether "incompleteness (is) such a defect of an ethical theory" (Roemer J. (2011), p. 370). So if the task is to choose a best element out of a class of technically feasible consumption paths one may be content with finding paths that dominate all other paths for a solely partial ordering, as e.g. the overtaking criterion considered above. Reducing demands on intertemporal evaluation criteria to a more modest level also reflects the view that it normally is quite unlikely that a single criterion integrates all properties that are normatively desirable. This problem is especially important in the case of infinitely many agents/generations. Since Diamond, P. (1965) thus impossibility results, which show the incompatibility of different plausible postulates, abound in the literature on intertemporal evaluation ${ }^{4}$. In particular, it has been shown that a social ordering which fulfils the equal treatment postulate and the strong Pareto principle cannot be represented by a cardinal social welfare function when there is an infinite number of generations (see Basu, K. and Mitra, T. (2003)). Nevertheless, having a numerical welfare measurement makes the determination of optimal consumption paths simpler and more transparent, which - from a purely technical viewpoint - is a non-negligible advantage of discounted utilitarianism. But it is questionable whether this argument can claim much ethical significance.

(ii) Applying a discounted utilitarian criterion is held to be an appropriate safeguard to avoid excessive savings and overburdening of earlier generations. This is particularly clear if, as in the example of the previous section, we start from a constant consumption path and any generation $t=2,3, \ldots$ has an equal increase in consumption $\epsilon$ when the first generation saves some amount $s$. Then given $\sum_{t=1}^{\infty} \delta_{t}<\infty$, the level of a welfare-improving investment in period 1 naturally is restricted by $\hat{s}=\left(\sum_{t=1}^{\infty} \delta_{t}\right) \epsilon$ which protects generation 1 . But, as explained above, along non-constant consumption paths the same effect may also be brought about with undiscounted social welfare functions. Moreover, if the utility function and the time discount factors are fixed, discounted utilitarianism mitigates but not necessarily avoids excessive savings of the first generation. We will show this using a linear growth model where the capital stock $k_{t+1}$ that generation $t$ hands over to generation $t+1$ is given by $k_{t+1}=$ $\alpha\left(k_{t}-c_{t}\right)$. Here, $\alpha$ is a productivity parameter which is assumed to be constant over time and which indicates the marginal rate of transformation between consumption in period $t$ and period $t+1$. If $k_{1}$ is the initially given capital stock of generation 1 then all consumption paths $\left(c_{1}, c_{2}, \ldots\right)$ are technically feasible for which

$$
\sum_{t=1}^{\infty} \frac{c_{t}}{\alpha^{t-1}} \leq k_{1}
$$

\footnotetext{
${ }^{3}$ We emphasize this point, because there is seemingly a remaining confusion of what is being discounted with the discount rate or the discount factor.

${ }^{4}$ One property of social orderings which the literature concentrates on but for which an ethical meaning is hard to detect is continuity w.r.t different topologies. See e.g. Svensson, L.-G. (1980), Asheim, G. B. and Buchholz, W. (2003) and Roemer J. (2011) for a discussion on this. Sakai, T. (2010) instead focuses on the compatibility between anonymity, strong Pareto and transitivity.
} 
holds. Just as before we now start from the Pareto optimal constant consumption path $(\bar{c}, \bar{c}, \ldots)$ (with $\bar{c}=\frac{\alpha-1}{\alpha} k_{1}$ for given $k_{1}$ ) and assume that generation 1 makes an additional saving of $s$ units of consumption. Then it directly follows from (5) that this enables any subsequent generation to increase its consumption by $\epsilon=(\alpha-1)$ s units. If we now consider the special case of an isoelastic utility function with $\eta=1$, i.e. $u(c)=\ln c$, the sum of discounted utilities flowing from saving $s$ is

$$
\ln (\bar{c}-s)+\sum_{t=2}^{\infty} \delta^{t-1} \ln (\bar{c}+(\alpha-1) s)=\ln (\bar{c}-s)+\frac{\delta}{1-\delta} \ln (\bar{c}+(\alpha-1) s)
$$

By an easy calculation it is shown that, assuming $\delta \alpha>1$, the level of savings which maximizes (6) is

$$
s^{*}=\frac{\delta \alpha-1}{\alpha-1} \bar{c}
$$

Even for quite plausible values of $\delta$ and $\alpha$, as e.g. $\delta=0.9$ and $\alpha=1.25$, (7) implies that generation 1 would be forced to sacrifice $45 \%$ of its initial consumption to make future generations better off. If the productivity parameter $\alpha$ goes to infinity, the level of savings according to equation (7) converges to $\delta \bar{c}$, which for a small time discount rate $\rho$ and a high $\alpha$ is close to $k_{1}$. This shows that time discounting with fixed parameters $\rho$ or equivalently $\delta$ will not necessarily prevent overburdening of early generations independent of the underlying technology. Concerning their ability to deal with the danger of excessive saving, the difference between undiscounted and discounted utilitarianism thus turns out to be less fundamental than might appear at first sight.

The first order conditions along an optimal path in the linear growth model of the previous section are

$$
u^{\prime}\left(c_{t+1}\right)=\frac{1}{\delta \alpha} u^{\prime}\left(c_{t}\right)
$$

which for an isoelastic utility function means

$$
c_{t+1}=(\delta \alpha)^{\frac{1}{\eta}} c_{t}
$$

It follows from (9) that the same optimal path is obtained for different combinations of $\delta$ and $\eta$. In particular, the optimal solution, which results for some originally given parameter values $\delta$ and $\eta$, can also be implemented without any pure time discount, i.e. $\delta=1$, by choosing a different inequality aversion parameter $\tilde{\eta}$ given by

$$
\tilde{\eta}=\frac{\eta \ln \alpha}{\ln \alpha+\ln \delta}
$$

This interchangeability of $\delta$ and $\alpha$ in addition confirms that the gap between undiscounted and discounted utilitarianism is less deep than usually suspected.

The ethically questionable properties of discounted utilitarianism which more or less mirror the advantages of undiscounted utilitarianism will now be discussed.

(i) Discounted utilitarian social welfare functions do not treat all generations equally as utility of later generations counts less than utility of earlier ones (which in the case of a finite number of agents would be a quite unusual assumption). Thus these criteria violate the basic postulate of intergenerational equity.

(ii) One cannot rule out the possibility that discounted utilitarianism leads to a non-sustainable development: Along consumption paths that maximize discounted 
utilitarian welfare (4) consumption of later generations may be smaller than that of earlier ones and, moreover, consumption may go to zero in the long run (see Dasgupta, P. and Heal, G. (1979), p.299 for the Dasgupta-Heal-Solow model). This phenomenon in general occurs if productivity of capital is low as compared to the discount rate. So it immediately follows from (8) that in the linear growth model consumption along an optimal is falling and converges to 0 if $\delta \alpha<1$. Declining consumption is inevitable for any constant discount factor $\delta<1$ if, as in the Dasgupta-Heal-Solow model with an exhaustible resource, marginal productivity of man-made capital converges to zero while the strictly positive utility discount rate $\rho$ is constant. Therefore, discounted utilitarianism not only is unfair towards later generations in the light of its normative foundations but also w.r.t. its possible consequences for the distribution of consumption across generations.

(iii) Discounted utilitarianism may violate the Pigou-Dalton transfer principle as the fundamental criterion for equality of distribution. This happens if the transfer goes from a rich early generation $t_{1}$ to a poor later generation $t_{2}$ whenever $\delta_{t_{1}} u^{\prime}\left(c_{t_{1}}\right)>\delta_{t_{2}} u^{\prime}\left(c_{t_{2}}\right)$. This condition is fulfilled if $\frac{c_{t_{2}}}{c_{t_{1}}}$ is close to one but $\frac{\delta_{t_{2}}}{\delta_{t_{1}}}$ is rather small.

\subsection{Hybrid criteria}

In the recent literature on intertemporal evaluation a lot of suggestions for new criteria have been developed to overcome some of the deficiencies of the standard criteria. The conceptually simplest approach is to combine two criteria in order to preserve some of the merits of both. Modifying an approach of Chichilnisky, G. (1996), Alvarez-Cuadrado, F. and Long, N. V. (2009) have suggested some composition of discounted utilitarianism with the maximin rule such that

$$
W\left(c_{1}, c_{2}, \ldots\right)=(1-\Theta) \sum_{t=1}^{\infty} \delta_{t} u\left(c_{t}\right)+\Theta \inf _{t=1,2, \ldots} u\left(c_{t}\right)
$$

emerges as a mixed Bentham-Rawls welfare function. Here, on the right-hand side of equation (11) the parameter $\Theta$ indicates the relative weight which maximin has in the aggregate criterion. A welfare function of this type makes it less likely than discounted utilitarianism alone that early generations enjoy a large increase in their well-being while the great many of future generations are driven into poverty. Thus a major possible shortcoming of discounted utilitarianism can be avoided and a more equitable balance of interest between the present and the future is achieved. But a sustainable development is not ensured in any case just if the parameter $\Theta$ is very small (see Alvarez-Cuadrado, F. and Long, N. V. (2009)), and the strong Pareto criterion is only fulfilled if the utility function $u(c)$ is bounded below. This, however, is not an innocuous assumption since in most empirical applications isoelastic utility functions $u(c)$ with inequality aversion $\eta \geq 1$ and thus $\lim _{c \rightarrow 0} u(c)=-\infty$ are used (see also the subsequent Section 3 for some justification of this). Moreover, if $\delta<1$, the social welfare function does not imply equal treatment of all generations such that anonymity as the basic postulate of intergenerational equity is also violated with mixed Bentham-Rawls criteria.

In contrast Zuber, S. and G. Asheim (2010) have devised a criterion which combines anonymity with discounting. The idea underlying this approach is that discounting does not depend on the period of time in which some level of consumption accrues but on the rank which the consumption level of a generation has in the whole consumption path. A problem with this rank-discounted utilitarianism is that, given an infinite number of generations, a ranking of consumption levels does not exist for all consumption streams, e.g. for any strictly decreasing path, such that additional constructions are required to extend and complete the social ordering and to get strong Pareto. Nevertheless, rank-discounted utilitarianism 
gives later generations more protection against rapacity of the earlier ones than the mixed Bentham-Rawls welfare functions which, from the perspective of sustainability, constitutes an important advantage. With the Asheim-Zuber criterion discounting serves as an "added expression of aversion to inequality" (Asheim, G. B. (2011), p. 8). But some further discussion seems to be required to justify rank-discounted utilitarianism in this respect as preferable to undiscounted utilitarianism.

Llavador, H., Silvestre, J. and J. Roemer (2008) reject the utilitarian framework completely and suggest a criterion in which an exogenously given constant growth rate $g$ of well-being is the objective that optimal paths have to fulfill. Proceeding in this unconventional way outside traditional welfare economics the maximin rule (where $g=0$ ) is generalized to a sustainable growth criterion which allows for economic progress and which thus cures the major defect of pure maximin. The question, however, is through which normative concepts the choice of some growth target $g$ may be motivated. Moreover, in some technological environments as the Dasgupta-Heal-Solow model, consumption growth with any constant positive rate is not possible which somewhat reduces the applicability of the Llavador-Silvestre-Roemer criterion.

\subsection{Some preliminary assessment}

All intertemporal social welfare functions that we have discussed have their pros and cons. Since maximin - with its exclusion of investment and economic progress - mostly deserves primarily attention for fixing basic ideas the real choice is between undiscounted and discounted utilitarianism. Which of these criteria is to be preferred thus is the major field of controversy in the scientific debate. Until now we have only compared these two types of evaluation criteria at an abstract level without saying anything about the parameter values that are needed to specify them. In particular, appropriate levels of the degree of inequality aversion $\eta$ incorporated in the isoelastic utility function $u(c)$ and the discount rate $\rho$ need to be chosen in order to make the criteria operational.

In simulation studies on climate change policy (as e.g. the DICE-model applied by Nordhaus, W. and J. Boyer (2000) to assess the economic impacts of climate change) $\eta$ and $\delta$ are, in the tradition of the descriptive school, usually determined by calibrating numerical growth models such that the Ramsey equation $r=\eta g+\delta$ (see e.g. Dasgupta, P. and Heal, G. (1979) or Stern, N. (2007)) is fulfilled given the empirically observed consumption growth rate $g$ and the real interest rate $r$. Proceeding this way (Nordhaus, W. (2007), p. 692) finds "the ethical reasoning on discount rates (...) largely irrelevant for the actual investments and negotiations about climate change". But from the viewpoint of the prescriptive school adopted here the parameter choice should also be made on the basis of normative principles. What at least is required "is adjusting certain parameters so as to reach a conclusion more in line with our intuitive judgements" (Rawls, J. (1971), p. 298). The possibility of determining these parameters by ethical reflections may also have some repercussions for the acceptability of the criteria as such. These additional, and, in contrast to the topics up to now in this paper, less familiar ethical issues will now be dealt with.

\section{Choice of parameters from a normative perspective}

The degree of inequality aversion of the utility function plays a central role for the specification of undiscounted, discounted and the hybrid criteria discussed above. The pattern of the time discount rate is only important for discounted utilitarianism and the hybrid versions. In the case of the mixed Bentham-Rawls criteria the weighing factor for the maximin part would have to be determined in addition. 


\subsection{Inequality aversion}

The Stern Review (see Stern, N. (2007)), in contrast to much previous work on climate change, explicitly addressed the ethical dimension of intergenerational evaluation and in principle adopted the equal treatment postulate for generations. Therefore, in Stern's approach the elasticity of marginal utility $\eta$ automatically became the main tool for bringing about an ethically acceptable balance of interest between different generations. But, somewhat surprisingly, the highly crucial choice of $\eta$ was not discussed explicitly from the ethical viewpoint. In this context the Review's reflections remained rather brief, and no convincing normative justification for specifically choosing $\eta=1$ as inequality aversion index for the main part of the empirical study was given. At the central place of the Report (see Stern, N. (2007), p. 184) there is only a short remark that employing $\eta=1$ is "in line with recent empirical estimates". Reference is made to two empirical papers by Stern, N. (1977) and Pearce, D. and D. Ulph (1995), but it is not explained in detail why such empirical estimates might at all be of much value for making ethical decisions. Ethically relevant arguments on the choice of $\eta$, in principle, might be found in three different ways.

(i) Adopting an ethical perspective does not exclude that the ethical values of existing people become the yardstick of evaluation. Then the debate is not about what seems to be just in the eyes of an impartial and detached ethical observer but which altruistic attitudes are prevalent in a society. This approach, which is in fact applied by Stern, N. (2007), combines prescriptive and descriptive elements. The observed data do not come from the market-place but from political decisions where ethical motivations on distributional issues manifest. Although many political decisions (e.g. on pension reform and the size of the government deficit) clearly affect distribution between generations, it is very difficult if not impossible to find out the level of the inequality aversion $\eta$ underlying just these decisions. Therefore, results from empirical studies on quite different topics in public policy as e.g. tax policy are transferred to the field of intergenerational distribution. The various studies on inequality aversion as expressed by income tax progressivity in a society suggest different values for $\eta$ which sometimes lie in the interval between 1 and 2 (see Evans, D. (2005)) but are lower than 1 in other studies (see Atkinson, A. and Brandolini, A. (2010)). These data certainly give some hint at existing normative beliefs on inequality. But individual attitudes towards income distribution within a society and in a certain period of time are multi-dimensional and also include aspects of effort and merit which are absent in the intergenerational context (where instead motivations as responsibility and stewardship play an important role). So it may be doubted whether estimates for $\eta$ that are obtained from income tax studies can easily be applied to intergenerational evaluation and climate policy.

(ii)The ethical acceptability of different values of $\eta$ can also be assessed by "thought experiments" through which their implications in specific theoretical models are assessed and, in the end, some "reflective equilibrium" (see at a general level Rawls, J. (1971) and with specific application to intergenerational equity Asheim, G. B. (2010)) on distributional norms might be achieved. In this vein Stern himself has conducted hypothetical "leaky bucket" experiments focusing on the tolerable losses when income transfers from a rich to a poor individual are made (see also Dietz, S. and Stern, N. (2008), p. 106). So e.g. if the giver were five times as rich than the receiver this accepted loss would be $96 \%$ for $\eta=2$. But note that for $\eta=1$ this loss also amounts to heavy $80 \%$ so that from this perspective Stern's preference for $\eta=1$ is not really substantiated.

In his critique of the Stern Report Dasgupta, P. (2008) has instead examined which consequences the choice of $\eta=1$ has for the rate of optimal growth in a linear Ramsey growth model where productivity of investment leads to an "incubation bucket" in the sense of Schelling, T. C. (1995). Under otherwise plausible assumptions (but without exogenous 
technical progress) Dasgupta showed that $\eta=1$ implies an extremely high savings rate amounting to almost $100 \%$ such that early generations would suffer extremely and a fair intergenerational balance would not be come about. In this way the traditional oversaving argument that usually is applied to disprove undiscounted utilitarianism is brought into play again, now to make judgments about sensible values of $\eta$. Then higher levels of $\eta$ (e.g. $\eta=2$ as proposed by Dasgupta, P. (2008) and other authors like Weitzman, M. (2007)) seem to be appropriate, which entail more equal optimal consumption paths and protect earlier generations from overburdening through excessive saving.

(iii) It is also possible to start from some explicitly formulated postulates (or "axioms") which a social welfare function should fulfill. Such a property is "circumstance solidarity" (Fleurbaey, M. (2008)) which in the context of growth theory means that no generation should lose when the technological conditions improve, i.e. in the linear growth model when productivity $\alpha$ increases. In order to satisfy this condition all values $\eta<1$ have to be excluded since with such a low inequality aversion the early generations would get lower consumption in the optimal solution when the $\alpha$ grows (see Buchholz, W. and Schumacher, J. (2010)). Therefore $\eta=1$ turns out to be the minimum degree of inequality aversion which is acceptable if circumstance solidarity is adopted as a normative postulate. In the framework of such an axiomatic approach one can consider other ethical postulates, such as e.g. non-envy criteria which are also familiar in ethical social choice theory. With this approach $\eta=1$ results when non-envy refers to absolute consumption levels of different generations. Alternatively, $\eta=2$ would be obtained if the non-envy comparison referred to relative consumption levels (for details see again Buchholz, W. and Schumacher, J. (2010)).

Different values of $\eta$ reflect value judgments on fair distributions, either at the level of voters or at the level of an ethical observer. These value judgments unavoidably have a subjective element such that it cannot be expected from the very beginning that a unique and uncontroversial estimate for $\eta$ is obtained. In spite of this general caveat, the thought experiments desbribed above support the view that low degrees of inequality aversion with values $\eta<1$ do not conform to ethical intuition. Recent empirical studies on revealed ethical preferences in tax policy give some support for this lower bound as most of them suggest values for $\eta$ lying somewhere between 1 and 2. Therefore, we can conclude that, from the perspective of both theoretical as empirical ethics, Stern, N. (2007) works with an extremely low degree of inequality aversion which gives the future (too) much weight.

Concerning an upper bound for $\eta$, things are less clear. No one in the debate around the Stern Review seems to advocate a value of $\eta$ being much higher than 3. But, as with the "trio of twos" from Weitzman, M. (2007), specific proposals for appropriate values of $\eta$ mostly follow from pure guesswork. Additional research therefore is required to find more precise foundations for ethically motivated choices of the parameter $\eta$.

\subsection{Pure time preference}

Determination of pure utility time discount factors $\left(\delta_{t}\right)_{t=1,2, \ldots}$ is even more problematic than of inequality aversion $\eta$. There are three approaches which - similar as in the case of $\eta$ - either refer to stated preferences of individuals or to normative ideas of an ethical observer.

(i) Aggregating opinions of more than 2000 economists Weitzman, M. (2001) obtained discount rates not being constant but falling to zero over time. Specifically, he got a discount rate of $4 \%$ for the next 5 years as the "immediate future", then $3 \%$ for the subsequent years until year 25 from now, $2 \%$ between year 26 and 75, $1 \%$ between year 76 and 300 and, finally thereafter for the "far-distant future", the discount rate 0 . But since Weitzman's study had the character of a black box and the motives of the respondents have not been explored systematically, it does not become transparent what the elicited discount 
rates really express. In particular, it is left open whether the answers reflect pure time preference as such or whether they are confounded by other aspects as inequality aversion or predictions of future growth rates. The difficulties to isolate pure time preference as a separate behavioral motive are well-known from the empirical literature on discounting in every-day individual choices. Trying to control for these additional factors normally leads to discount rates that are substantially lower than those originally inferred (see Frederick, S., Loewenstein, G. and O'Donoghue, T. (2002)).

Another difficulty with Weitzman's approach concerns his specific method to aggregate the elicited time discount rates. To illustrate this problem we consider a simple example, in which there are two respondents $a$ and $b$. Agent $a$ has the constant time preference rate $\rho^{a}=0$ such that for that agent's time discount factors $\delta_{t}^{a}=1$ holds for all periods $t=1,2, \ldots$. Agent $b$ instead has the time preference rate $\rho^{b}=1$ which implies $\delta_{t}^{b}=\left(\frac{1}{2}\right)^{t-1}$ in period $t$. Taking the average of these both discount factors gives

$$
\delta_{t}^{m}=\frac{1}{2} \cdot 1+\frac{1}{2} \cdot\left(\frac{1}{2}\right)^{t-1}
$$

as discount factor for period $t=1,2, \ldots$. Clearly, $\lim _{t \rightarrow \infty} \delta_{t}^{m}=1$ which implies that the discount rates $\rho_{t}^{m}$ obtained from this averaging procedure converge to zero in the long run. A similar result holds when there are not different opinions on time preference but when discount rates are uncertain (Weitzman, M. (1998)). Our small theoretical exercise shows that Weitzman's main result, i.e. that costs and benefits accruing in the far-distant future should be discounted at a very low and even at the lowest possible rate, does not so much rest upon the collected opinions on appropriate discount rates. Rather it is a direct consequence of his aggregation method which is not at all naturally given. So, alternatively, one could simply average the different stated discount rates, which based on Weitzman's data would give a constant discount rate of about $4 \%$ or consider - as suggested by Gollier, C. (2004) - the average of future instead of present values. This would change the outcome totally since then the far-distant future would have to be discounted not at the lowest but at the highest possible rate. In any case it is required that the ideas, and possibly their normative content, lying behind the different aggregation methods are explained and motivated carefully (see Buchholz, W. and Schumacher, J. (2008) for some comparison of Weitzman's and Gollier's aggregation methods and Gollier, C. (2010) for an attempt to reconcile both approaches). Otherwise, the aggregation procedure appears to be arbitrary and its results thus only are of limited value.

(ii) Assume that (as in the classical approach by Harsanyi, J. (1955)) there is an ethical observer behind a veil of ignorance who applies expected utility theory to compare different distributions across generations. If in this situation the "states of the world" will not occur with the same probability she will take these differences into account - even if, in principle, she is impartial and does not favor any generation. Thus it may be ethically well acceptable to give later generations some lower weight in social evaluation since there is some risk that mankind (e.g. by an asteroid or by a devastating epidemic disease) is extinct. Later generations then would not exist and thus were not able to enjoy the fruits of savings today. If this risk of extinction from one period to the next is constant over time and equal to $\pi$ the discount factor in period $t$ is the survival probability $\delta_{t}=(1-\pi)^{t-1}$. Estimation of $\pi$ obviously is very speculative and a matter of subjective belief. In particular, Stern, N. (2007) has assumed a probability of $10 \%$ that civilization may be extinct within one century which leads to the annual utility discount rate $\rho=0.1 \%$ being used in the Stern Review. From a different ethical 
perspective one could, however, raise some doubts whether it is justified at all to make such a bet on the existence of future generations.

(iii) If we return to the linear growth model described above it becomes clear that non-decreasing and thus sustainable consumption paths emerge as optimal solutions if $\delta \alpha>1$ , i.e. $\delta>\frac{1}{\alpha}$ or $\rho<\alpha-1$, which means that the time discount rate is lower than the economy's productivity. Growth of consumption along an optimal path is reduced if $\rho$ is increased. If $\delta=\frac{1}{\alpha}$ or $\rho=\alpha-1$ a constant consumption path is obtained. Playing around with $\rho$ in this way means that the time discount rate which is considered to be appropriate depends on the underlying technology and thus becomes endogenous. As in Llavador, H., Silvestre, J. and J. Roemer (2008) the ethical objective then is some desirable speed of growth which is also in line with Rawls, J. (1971) "just savings principle" and his justification of pure time discount. A problem with this approach, however, is that the familiar idea that time discount rates are part of fixed social preferences being independent of the technological conditions has to be abandoned completely. But by adjusting the time discounting to the productivity of capital at least gives some upper bound for the admissible discount rate if a non-sustainable development is to be ensured.

\section{Conclusion}

If the choice of a specific intertemporal evaluation criterion is seen to be an ethical one, which is the viewpoint taken in this article, an uncontroversial solution clearly does not exist. Following M. Weber's famous "Wertfreiheitspostulat" it can never be decided on an objective scientific base what should be considered as an equitable distribution between agents in general and among generations as an important special case. Nevertheless, our considerations allow some tentative conclusions on the adequacy of intertemporal evaluation criteria in climate change policy.

(i) Rejection of the undiscounted in favor of discounted utilitarianism, as often suggested in the literature, seems neither necessary nor desirable. In the first place, undiscounted utilitarianism implies equal treatment of all generations and ensures sustainability. These are real virtues of an evaluative criterion. In the second place, it does not completely rule out making choices among increasing consumption paths - in particular, the introduction of pure time discount is not really required to avoid the excessive saving problem that is typically attributed to undiscounted utilitarianism and, indeed, often seen as its major shortcoming. Moreover, endorsement of undiscounted utilitarianism at a basic level need not preclude the application of a - possibly very small - pure time discount rate in order to account for the uncertainty of costs and benefits falling on future generations. Irrespective of the level of the time discount rate such a kind of "discounted utilitarianism light" gives numerical representability of the underlying social ordering which, from a practical perspective, faciliates application of the evaluation criterion to cost-benefit analysis and, from a theoretical perspective, ensures completeness of the social ordering and fulfillment of the strong Pareto principle. Seen from such a pragmatic viewpoint the extensive discussion on impossibility results in the case of infinitely many generations becomes a little redundant and some doubts may arise to which degree the recently developed more complicated hybrid criteria represent an improvement. So, partly for the same and partly for additional reasons as put forward by Stern, N. (2007) himself, we are essentially backing Stern's basic preference for undiscounted utilitarianism which gives the ethical dimension of the problem due respect and seems to represent a substantial shift of paradigm in the literature on intertemporal evaluation. 
(ii) Concerning the parameters that specify the social welfare function we consequently accept Stern's choice of a very low pure time discount rate $\rho$ but reject his choice of the inequality aversion parameter $\eta$ as too low. Various thought experiments conducted in growth theoretic models as well as empirical observations of actual political decisions on redistribution suggest values of $\eta$ that are higher than 1 and mostly lie closer to 2 than to 1 . By now, unfortunately, no clear-cut normative criteria seem to be available which might help to determine more precise values for $\eta$. Thus there is much room left for the choice of $\eta$. This suggests that in specific applications sensitivity tests with different values of $\eta$ are advisable. Employing some higher level of $\eta$ gives less weight to the future. In the context of climate policy this means that the abatement of greenhouse gas emissions could happen more slowly than demanded by Stern, N. (2007). Applying Stern's approach but working with higher and more plausible values of $\eta$, would help to approach the different positions and thus take much edge off the heated controversy on the Stern Review and its urgent call for strong and immediate action in climate change policy.

Even though he uses the descriptive approach on discounting, Nordhaus, W. (2007) makes essentially the same point when he conducts a further run of his DICE integrated assessment model with the same near zero pure time discount rate $\rho$ as in the Stern Report but a much higher elasticity of marginal utility $\eta=3$. With these parameter values Nordhaus obtains quite similar results as in his original calculations which had been based on $\rho=1.5 \%$ and $\eta=2$. In both simulations the "price of carbon" which equilibrates the marginal cost of environmental damages with the marginal abatement costs would lie between 200 and 300 \$ per ton of carbon by the end of this century. This price would be much lower than with Stern's original parameter choice where the price of carbon would rise steeply to almost $1000 \$$ which makes the climate change problem appear much more dramatic. In his postscript to the Stern Review, Stern, N. (2008) himself presents related results concerning the interchangeability between $\eta$ and $\rho$ showing, e.g., that increase of $\eta$ from 1 to 1.25 may have a similar effect on the monetary costs of climate change as an increase of the pure time discount rate $\rho$ from 0.1 $\%$ to $0.5 \%$.

These simulation studies on the costs and benefits of climate change policy thus confirm a basic and empirically quite relevant message of this paper: The question whether to use undiscounted or discounted utilitarianism is to some degree futile concerning practical policy implications. What in the end matters much more is the selection of specific parameter values. However, it is hard to provide some well-founded normative justification for the precise values chosen.

\section{Acknowledgments}

This paper is partly based on presentations at seminars at the Free University Berlin, the European University Viadrina at Frankfurt (Oder) and the Centre for European Economic Research (ZEW), Mannheim. We want to thank the participants of these seminars for their suggestions. Special thanks go to Geir Asheim for many stimulating discussions on the topics of this paper, to Richard Cornes for his careful reading of an earlier draft and his very helpful comments and to Anthony Atkinson for very helpful suggestions.

\section{References}

Aldy, J., Krupnick, A., Newell, R., Parry, I. and Pizer, W. (2010): Designing Climate Mitigation Policy, in: Journal of Economic Literature, Vol. 48, pp. 903-934 
Alvarez-Cuadrado, F. and Long, N. V.. (2009): A Mixed Bentham Rawls Criterion for Intergenerational Equity: Theory and Implications, in: Journal of Environmental Economics and Management, Vol. 58, pp. 154-168

Arrow, K. (1999): Discounting, Morality and Gaming, in: Discounting and Intergenerational Equity, ed. D. R. Portney and P. Weyant, pp. 13-21, Resources for the Future, Washington D.C.

Asheim, G. B. (1991): Unjust Intergenerational Allocations, in: Journal of Economic Theory, Vol. 54, pp. 350-371

Asheim, G. B., Buchholz, W. and Tungodden, B. (2001): Justifying Sustainability, in: Journal of Environmental Economics and Management, Vol. 41, pp. 252-268

Asheim, G. B. and Buchholz, W. (2003): The Malleability of Undiscounted Utilitarianism as a Criterion for Intergenerational Justice, in: Economica, Vol. 70, pp. 405-422

Asheim, G. B. (2010): Intergenerational Equity, in: Annual Review of Economics, Vol. 2, pp. 197-222

Asheim, G. B. (2011): Discounting while Treating Generations Equally, in: University of Oslo, Department of Economics, Discussion Paper

Atkinson, A. (1970): On the Measurement of Inequality, in: Journal of Economic Theory, Vol. 2, pp. $244-263$

Atkinson, A. (2011): The Restoration of Welfare Economics , in: American Economic Review, Papers \& Proceedings, Vol. 101, pp. 157-161

Atkinson, A. and Brandolini, A. (2010): On Analyzing the World Distribution of Income, in: World Bank Economic Review, Vol. 24, pp. 1-37

Basu, K. and Mitra, T. (2003): Aggregating Infinite Utility Streams with Intergenerational Equity: The Impossibility of Being Paretian, in: Econometrica, Vol. 32, pp. 1557-1563

Blackorby, C. , Bossert, W. and Donaldson, D. (1995): Intertemporal Population Ethics: Critical-Level Utilitarian Principles, in: Econometrica, Vol. 63, pp. 1303-1320

Buchholz, W. and Schumacher, J. (2008): Discounting the Long-Distant Future: A Simple Explanation for the Weitzman-Gollier-Puzzle, in: CESifo Working Paper, No. 2357

Buchholz, W. and Schumacher, J. (2010): Discounting and Welfare Analysis over Time: Choosing the Eta, in: European Journal of Political Economy, Vol. 26, pp. 372-385

Chakravarty, S. (1969) : Capital and Development Planning, MIT Press, Cambridge, MA

Chichilnisky, G. (1996): An Axiomatic Approach to Sustainability, in: Social Choice and Welfare, Vol. 13, pp. 231-257

d'Aspremont, C. and Gevers, L. (1977): Equity and the Informational Basis of Collective Choice, in: Review of Economic Studies, Vol. 44, pp. 199-209

Dasgupta, P. and Heal, G. (1979): Economic Theory and Exhaustible Resources, Cambridge University Press, Cambridge, UK

Dasgupta, P. (2008): Discounting Climate Change, in: Journal of Risk and Uncertainty, Vol. 37, pp. 141-169

Diamond, P. (1965): The Evaluation of Infinite Utility Streams, in: Econometrica, Vol. 33, pp. 170-177

Dietz, S. and Stern, N. (2008): Why Economic Analysis Supports Strong Action on Climate Change: A Response to the Stern Review's Critics, in: Review of Environmental Economics and Policy, Vol. 2, pp. 94-113

Evans, D. (2005): The Elasticity of Marginal Utility of Consumption: Estimates for 20 OECD Countries, in: Fiscal Studies, Vol. 26, pp. 197-224

Fleurbaey, M. (2008): Fairness, Responsibility and Welfare, Oxford University Press, Oxford and New York

Frederick, S., Loewenstein, G. and O'Donoghue, T. (2002): Time Discounting and Time Preference: A Critical Review, in: Journal of Economic Literature, Vol. 40, pp. 351-401 
Gollier, C. (2004): Maximizing the Expected Net Future Value as an Alternative Strategy to Gamma Discounting, in: Financial Research Letters, Vol. 1, pp. 85-89

Gollier, C. (2010): Expected Net Present Value, Expected Net Future Value and the Ramsey Rule, in: Journal of Environmental Economics and Management, Vol. 59, pp. 142-148

Harsanyi, J. (1955): Cardinal Welfare, Individualistic Ethics, and Interpersonal Comparisons of Welfare, in: Journal of Political Economy, Vol. 63, pp. 309-321

Kaplow, L. (2010): Concavity of Utility, Concavity of Welfare, and Redistribution of Income, in: International Tax and Public Finance, Vol. 17, pp. 25-42

Kaplow, L., Moyer, E. and Weisbach, D. A. (2010): The Social Evaluation of Intergenerational Policies and Its Application to Intregrated Assessment Models of Climate Change, in: The B.E. Journal of Economic Analysis and Policy, Vol. 10, Article 7

Llavador, H., Silvestre, J. and Roemer, J. (2008): The Ethics of Distribution in a Warming Planet, in: Yale University Working Paper

Nordhaus, W. and Boyer, J. (2000): Warming the World: Economic Models of Global Warming, MIT Press, Cambridge, MA, and London

Nordhaus, W. (2007): A Review of the Stern Review on the Economics of Climate Change, in: Journal of Economic Literature, Vol. 45, pp. 686-702

Pearce, D. and Ulph, D. (1995): A Social Discount Rate for the United Kingdom, in: Global Environmental Change Working Paper GEC-1995-01

Ramsey, F. (1928): A Mathematical Theory of Saving, in: Economic Journal, Vol. 38, pp. 543-559

Rawls, J. (1971): A Theory of Justice, Harvard University Press, Cambridge, MA

Roemer, J. (1996): Theories of Distributive Justice, Harvard University Press, Cambridge, MA

Roemer, J. (2011): The Ethics of Intertemporal Distribution in a Warming Planet, in: Environmental and Resource Economics, Vol. 48, pp. 363-390

Sakai, T. (2010): Intergenerational Equity and an Explicit Construction of Welfare Criteria, in: Social Choice and Welfare, Vol. 35, pp. 393-414

Schelling, T. C. (1995): Intergenerational Discounting, in: Energy Policy, Vol. 23, pp. 395-401

Sidgwick, H. (1874): The Methods of Ethics, Oxford University Press, Oxford, UK

Solow, R. (1974): Intergenerational Equity and Exhaustible Resources, in: Review of Economic Studies, Vol. 41, pp. 29-45

Stern, N. (1977): The Marginal Valuation of Income, in: Studies in Modern Economic Analysis: The Proceedings of the Association of University Teachers of Economics, ed. M. J. Artis and A. R. Nobay, pp. 209-254, Basil Blackwell, Oxford, UK

Stern, N. (2007): The Economics of Climate Change: The Stern Review, Cambridge University Press, Cambridge, UK

Stern, N. (2008): The Economics of Climate Change, in: American Economic Review, Vol. 98, pp. $1-37$

Svensson, L.-G. (1980): Equity among Generations, in: Econometrica, Vol. 48, pp. 1251-1256

Weizsäcker, C. C. (1965): Existence of Optimal Programs of Accumulation for an Infinite Time Horizon, in: Review of Economic Studies, Vol. 32, pp. 85-104

Weitzman, M. (1998): Why the Far-Distant Future Should be Discounted at Its Lowest Possible Rate, in: Journal of Environmental Economics and Management, Vol. 36, pp. 201-208

Weitzman, M. (2001): Gamma Discounting, in: American Economic Review, Vol. 91, pp. 260-271

Weitzman, M. (2007): A Review of The Stern Review on the Economics of Climate Change, in: Journal of Economic Literature, Vol. 45, pp. 703-724

Zuber, S. and Asheim, G. B. (2010): Justifying Social Discounting: The Rank-Discounted Utilitarian Approach, in: CESifo Working Paper, No. 3192 


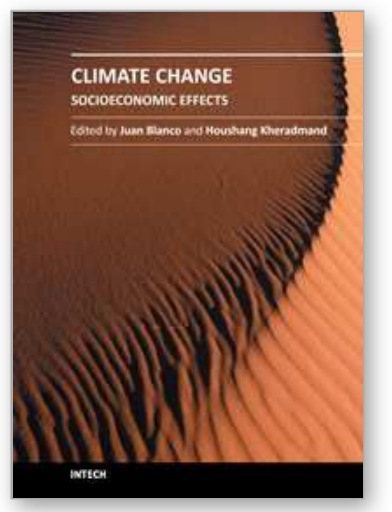

\author{
Climate Change - Socioeconomic Effects \\ Edited by Dr Houshan Kheradmand
}

ISBN 978-953-307-411-5

Hard cover, 454 pages

Publisher InTech

Published online 09, September, 2011

Published in print edition September, 2011

This book shows some of the socio-economic impacts of climate change according to different estimates of the current or estimated global warming. A series of scientific and experimental research projects explore the impacts of climate change and browse the techniques to evaluate the related impacts. These 23 chapters provide a good overview of the different changes impacts that already have been detected in several regions of the world. They are part of an introduction to the researches being done around the globe in connection with this topic. However, climate change is not just an academic issue important only to scientists and environmentalists; it also has direct implications on various ecosystems and technologies.

\title{
How to reference
}

In order to correctly reference this scholarly work, feel free to copy and paste the following:

Wolfgang Buchholz and Michael Schymura (2011). Intertemporal Evaluation Criteria for Climate Change Policy: Basic Ethical Issues, Climate Change - Socioeconomic Effects, Dr Houshan Kheradmand (Ed.), ISBN: 978-953-307-411-5, InTech, Available from: http://www.intechopen.com/books/climate-change-socioeconomiceffects/intertemporal-evaluation-criteria-for-climate-change-policy-basic-ethical-issues

\section{INTECH}

open science | open minds

\section{InTech Europe}

University Campus STeP Ri

Slavka Krautzeka 83/A

51000 Rijeka, Croatia

Phone: +385 (51) 770447

Fax: +385 (51) 686166

www.intechopen.com

\section{InTech China}

Unit 405, Office Block, Hotel Equatorial Shanghai

No.65, Yan An Road (West), Shanghai, 200040, China 中国上海市延安西路65号上海国际贵都大饭店办公楼 405 单元

Phone: +86-21-62489820

Fax: +86-21-62489821 
(C) 2011 The Author(s). Licensee IntechOpen. This chapter is distributed under the terms of the Creative Commons Attribution-NonCommercialShareAlike-3.0 License, which permits use, distribution and reproduction for non-commercial purposes, provided the original is properly cited and derivative works building on this content are distributed under the same license. 